\title{
Anti-oxidative stress regulator NF-E2-related factor 2 mediates the adaptive induction of antioxidant and detoxifying enzymes by lipid peroxidation metabolite 4-hydroxynonenal
}

Ying Huang ${ }^{1}$, Wenge $\mathrm{Li}^{1,2}$ and Ah-Ng Tony Kong ${ }^{1 *}$

\begin{abstract}
Background: NF-E2-related factor 2 (NRF2) regulates a battery of antioxidative and phase II drug metabolizing/ detoxifying genes through binding to the antioxidant response elements (ARE). NRF2-ARE signaling plays a central role in protecting cells from a wide spectrum of reactive toxic species including reactive oxygen/nitrogen species (RONS). 4-hydroxylnonenal (4-HNE) is a major end product from lipid peroxidation of omega-6 polyunsaturated fatty acids (PUFA) induced by oxidative stress, and it is highly reactive to nucleophilic sites in DNA and proteins, causing cytotoxicity and genotoxicity. In this study, we examined the role of NRF2 in regulating the 4-HNE induced gene expression of antioxidant and detoxifying enzymes.
\end{abstract}

Results: When HeLa cells were treated with 4-HNE, NRF2 rapidly transloated into the nucleus, as determined by the distribution of NRF2 tagged with the enhanced green fluorescent protein (EGFP) and increased NRF2 protein in the nuclear fraction. Transcriptional activity of ARE-luciferase was significantly induced by 0.01-10 $\mu \mathrm{M}$ of 4-HNE in a dose-dependent manner, and the induction could be blocked by pretreatment with glutathione (GSH). 4-HNE induced transcriptional expression of glutathione S-transferase (GST) A4, aldoketone reductase (AKR) $1 \mathrm{C} 1$ and heme oxygenase-1 (HO-1), and the induction was attenuated by knocking down NRF2 using small interfering RNA.

Conclusions: NRF2 is critical in mediating 4-HNE induced expression of antioxidant and detoxifying genes. This may account for one of the major cellular defense mechanisms against reactive metabolites of lipids peroxidation induced by oxidative stress and protect cells from cytotoxicity.

Keywords: NRF2, 4-hydroxynonenal (4-HNE), Antioxidant response element (ARE), Oxidative stress

\section{Background}

Polyunsaturated fatty acids (PUFA), essential components of cell membrane, are susceptible to oxidation initiated by free radicals [1]. 4-hydroxylnonenal (4-HNE) is an end product from lipid peroxidation of omega- 6 (n-6) PUFA [2]. The physiological concentration of 4-HNE is generally at the low micromolar level, but is remarkably increased under continuous oxidative stress [3]. As an $\alpha, \beta$-unsaturated aldehyde, 4-HNE is highly reactive to a variety of nucleophilic sites in DNA and

\footnotetext{
* Correspondence: kongt@pharmacy.rutgers.edu

'Department of Pharmaceutics, Center for Cancer Prevention Research, Ernest Mario School of Pharmacy, Rutgers, the State University of New Jersey, 160 Frelinghuysen Road, Piscataway, NJ 08854, USA

Full list of author information is available at the end of the article
}

proteins [4]. Exposure to excessive 4-HNE can cause cytotoxicity, inactivation of enzymes, redox imbalance and activation of multiple signaling events, and 4-HNE is implied in the detrimental pathogenesis of a number of degenerative diseases including cancer [5,6]. Several metabolic pathways are involved in the detoxification of 4-HNE, including conjugation with glutathione (GSH) catalyzed by glutathione S-transferases (GST) and reduction of the aldehyde group to corresponding alcohol by aldoketone reductases (AKR) [5].

Eukaryotic cells have developed highly efficient machineries to counteract oxidative stress from environmental insults and aerobic metabolisms [7]. Antioxidant response elements $(A R E)$ are identified in the regulatory

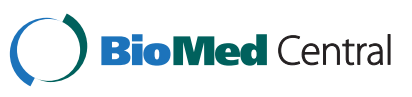




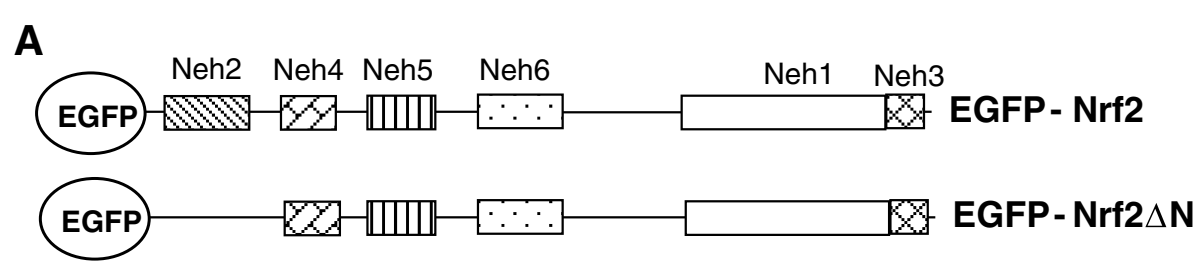

B
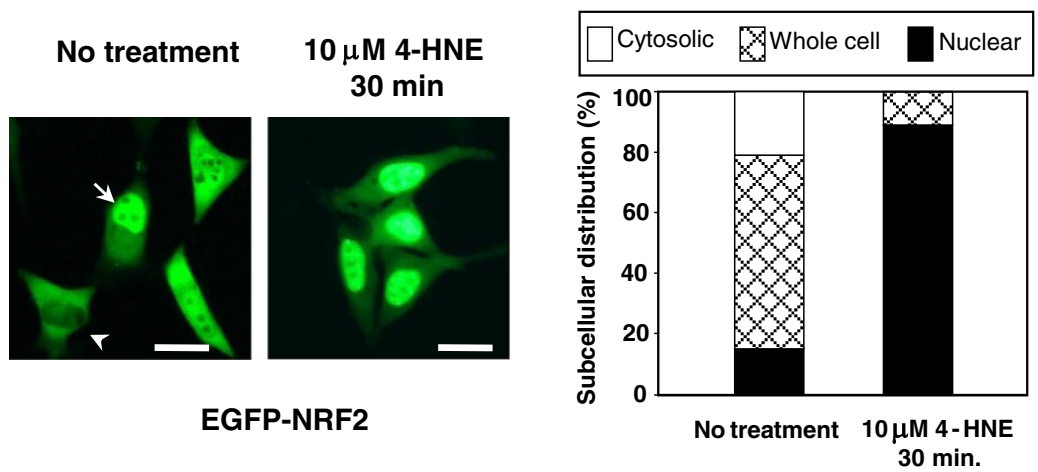

C $\quad$ 4-HNE

EGFP-NRF2

$30 \mathrm{~min}$.
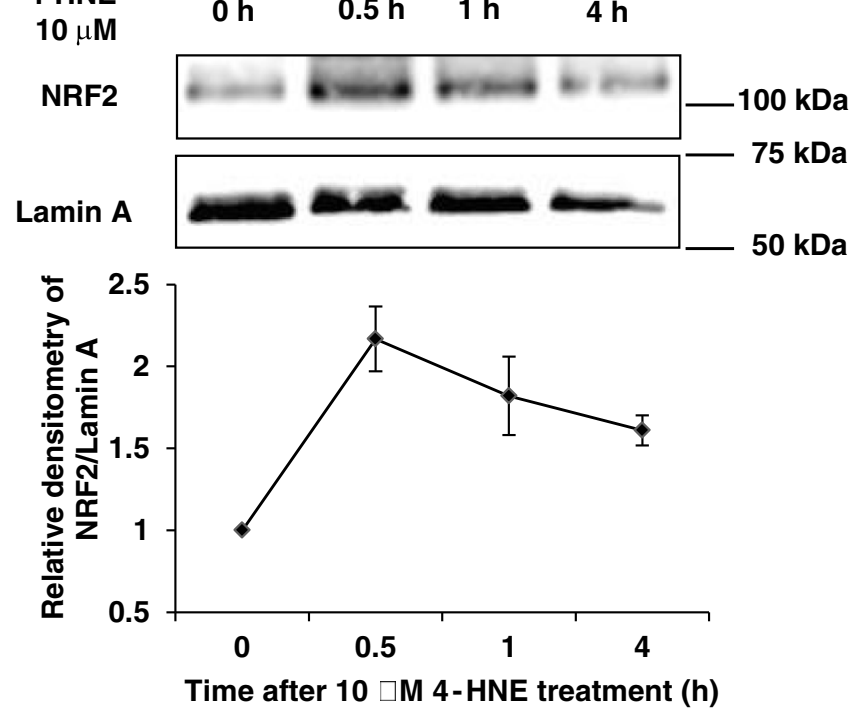

D
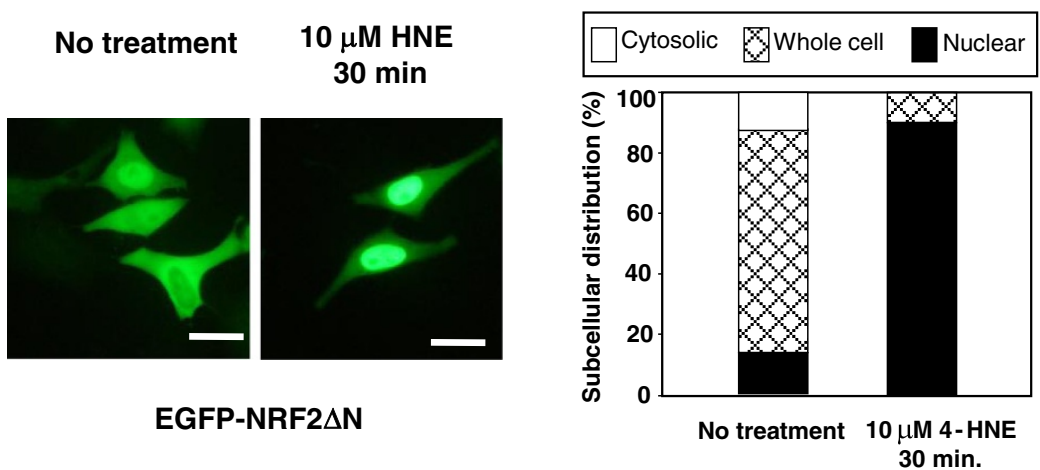

Figure 1 (See legend on next page.) 
(See figure on previous page.)

Figure 1 4-HNE treatment induces NRF2 nuclear translocation. (A) The schematic diagram showing the structures of NRF2 constructs used in the study. (B) Under the untreated condition, EGFP-NRF2 exhibited a mixed pattern of nuclear (arrow), whole cell and cytosolic (arrowhead) distribution. After treatment of $10 \mu \mathrm{M}$ 4-HNE for $30 \mathrm{~min}$, a predominantly nuclear distribution was observed. Scale bar: $10 \mu \mathrm{m}$. (C) Time course of nuclear NRF2 accumulation after $10 \mu \mathrm{M}$ 4-HNE treatment. *: $P<0.05$. (D) Deletion of the KEAP1-binding domain (NRF2 $\Delta \mathrm{N}$ ) did not affect 4-HNE induced nuclear translocation of NRF2.

region of many cytoprotective genes that encode phase II drug metabolizing/detoxifying enzymes, antioxidant enzymes and phase III transporters [8,9]. When oxidative stress is elevated, NF-E2-related factor 2 (NRF2) will be activated to trigger gene expression through binding to $A R E$ [10]. Subsequently, it leads to enhanced cellular capability to remove excess electrophiles and restore redox homeostasis [11].

NRF2 activity is regulated in part by a repressor protein, Kelch-like ECH-associated protein 1 (KEAP1), which retains NRF2 in the cytoplasm and mediates its degradation under homeostatic conditions [12]. Stimuli such as dietary antioxidants, heavy metals and reactive oxygen species (ROS) can disrupt the NRF2-KEAP1 binding and induce nuclear translocation of NRF2 where it dimerizes with small Maf proteins and binds to $A R E$ [12]. In addition, some studies have shown that the subcellular distribution of NRF2 can also be controlled by the net driving force of nuclear location signals (NLS) and nuclear export signals (NES) [13] and phosphorylation of NRF2 [7] .

In this study, we investigated the role of NRF2 in regulating the gene expression of antioxidant and detoxifying enzymes upon the exposure to 4-HNE. Our results show that NRF2 rapidly translocates into nucleus after exposure to 4-HNE and induces transcriptional activity of $A R E$ and mRNA expressions of AKR1C1, GSTA4 and heme oxygenase-1 (HO-1). The induction of these detoxifying enzymes is diminished when NRF2 is knocked down using small interfering RNA.

\section{Results}

NRF2 translocates into the nucleus after 4-HNE treatment When expressed in HeLa cells, NRF2 tagged with the enhanced green fluorescent protein (EGFP) exhibited a heterologous distribution pattern (Figure 1B). Cell percentage assay showed that $64 \%$ of cells exhibited a whole cell distribution pattern. About $15 \%$ of cells showed a nuclear distribution (Figure 1B, arrow) and 21\% of cells showed a cytosolic distribution (Figure 1B, arrowhead). After treatment with $10 \mu \mathrm{M}$ 4-HNE for $30 \mathrm{~min}$, nearly $90 \%$ of cells exhibited a nuclear distribution (Figure 1B), indicating robust nuclear translocation of NRF2.

To further confirm the nuclear translocation effect elicited by 4-HNE, we examined the nuclear NRF2 protein level by Western blotting analyses. HeLa cells were treated with $10 \mu \mathrm{M}$ 4-HNE for $0,0.5,1$ and $4 \mathrm{~h}$. 4-HNE markedly elevated the nuclear NRF2 protein level, with the highest accumulation at $0.5 \mathrm{~h}$ after treatment (Figure 1C). Similar effects have been observed in PC12 cells and vascular endothelial cells $[14,15]$.

Next, the N-terminal truncation mutant of NRF2 (EGFP-NRF2 $\triangle N$, Figure 1D) lacking the KEAP1 domain, was expressed in HeLa cells. Under the unstressed condition, EGFP-NRF2 $\triangle \mathrm{N}$ demonstrated a heterologous distribution pattern (Figure 1D). Treatment with $10 \mu \mathrm{M} 4$-HNE (30 min) converted the distribution of EGFP-NRF2 $\triangle \mathrm{N}$ to a predominant nuclear pattern (Figure 1D). Previous study showed that no $\mathrm{NRF} 2 \Delta \mathrm{N} / \mathrm{KEAP} 1$ binding was detected when NRF $2 \Delta \mathrm{N}$ was co-expressed with KEAP1 [16]. Since NRF2 $\Delta N$ is free from KEAP1 sequestration in the cytosol, the NRF $2 \Delta \mathrm{N}$ distribution can be deemed as free floating in the cell. These results show that 4-HNE can directly affect the subcellular distribution of NRF2 into the nucleus.

\section{ARE-luciferase activity increases after 4-HNE treatment}

To determine whether the nuclear accumulation of NRF2 could increase the transcriptional activity of $A R E$, we co-expressed $0.5 \mu \mathrm{g}$ pcDNA3.1-NRF2 with $0.25 \mu \mathrm{g}$ $A R E$-luciferase reporter in HeLa cells. Twenty-four hours after transfection, cells were treated with $0,0.01$, $0.1,1,10 \mu \mathrm{M} 4-\mathrm{HNE}$ for $30 \mathrm{~min}$ and then cultured in fresh medium for $6 \mathrm{~h}$. HNE treatments elicited significant $A R E$-luciferase inductions in a dose-dependent manner (Figure 2A).

HepG2-C8 cells with stably expressed pARE-TIluciferase constructs [17] were treated with 0 and $10 \mu \mathrm{M}$ 4-HNE for $18 \mathrm{~h}$. ARE-luciferase activity was significantly induced with $10 \mu \mathrm{M}$ 4-HNE treatment compared with the untreated cells (Figure 2B). Since the conjugation to GSH is the major metabolism pathway for 4-HNE, it will result in a net loss of intracellular GSH and redox imbalance. We found that when cells were pretreated with $5 \mathrm{mM} \mathrm{GSH}$, the induction of $A R E$ luciferase activity was completely blocked (Figure $2 \mathrm{~B}$ ).

\section{NRF2 is critical in regulating the expression of detoxifying genes}

When HeLa cells were treated with 4-HNE, in agreement with the enhanced ARE-luciferase activity, RT-PCR results showed that 4-HNE induced the transcription of AKR1C1, GSTA4 and HO-1 in a dose-dependent manner 

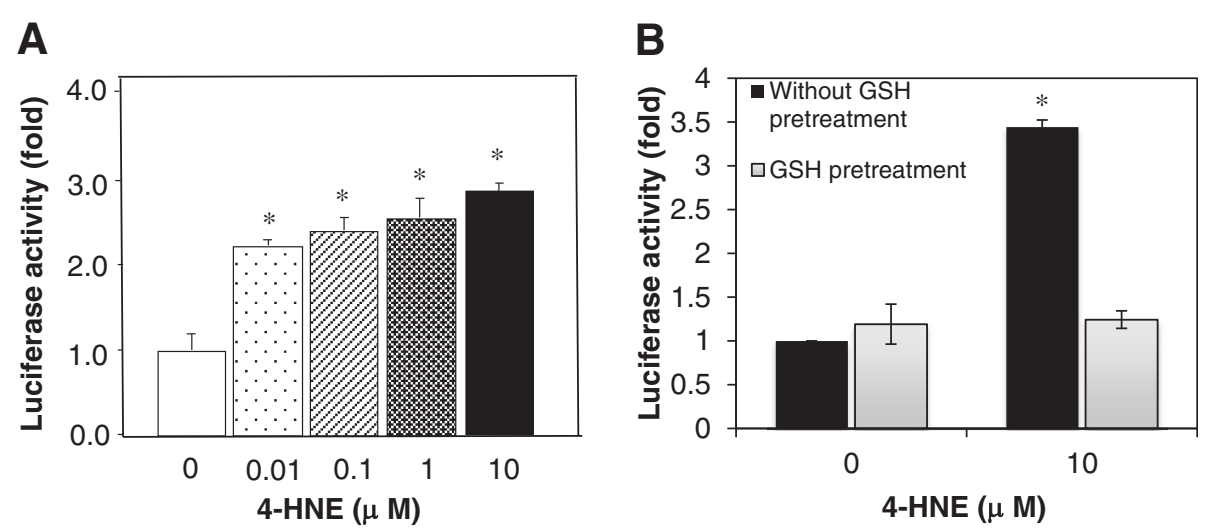

Figure 2 ARE-luciferase activity significantly increases by 4-HNE treatment. (A) HeLa cells were transiently transfected with ARE-luciferase construct for $24 \mathrm{~h}$ and treated with 0.01-10 $\mathrm{MM}$ 4-HNE. Cells were harvested and lysed after 6 h, and luciferase activity was measured. (B) HepG2 cells stably expressed with ARE-luciferase reporter gene were treated with $10 \mu \mathrm{M} 4$-HNE with or without $2 \mathrm{~h}$ pretreatment of 5 mM GSH. Cells were harvested and lysed after $18 \mathrm{~h}$, and luciferase activity was measured. Relative fold of induction was obtained as compared to the untreated cells. *: $P<0.05$

(Figure 3A). To examine whether the induction of these detoxifying and antioxidant genes was dependent on NRF2, HeLa cells were transfected with NRF2 specific siRNA or nonspecific siRNA as a control. NRF2 expression was down-regulated by the siRNA transfection (Figure $3 \mathrm{~B}$ ). In the cells transfected with control siRNA, the expression of $A K R 1 C 1$, GSTA4 and HO- 1 was markedly induced by $10 \mu \mathrm{M} 4-\mathrm{HNE}$, while in the cells transfected with NRF2 siRNA, the induction of these genes was attenuated (Figure $3 \mathrm{~B}$ ).

\section{Discussion}

It is well recognized that our body has a comprehensive antioxidant system to counter oxidative stress. 4-HNE, an oxidative stressor, causes adaptive induction of detoxifying enzymes such as AKR1C1 and GSTA4 in different cell lines $[18,19]$, although the molecular pathway is not fully understood. The common feature of these detoxifying genes is that they have $A R E$-like sequences in their 5'-flanking regions [20,21]. In this study, we demonstrate that NRF2 mediates 4-HNE induced gene expression of key antioxidant and detoxifying enzymes, resulting in enhanced 4-HNE metabolism.

4-HNE is a highly reactive electrophile, and several studies have reported that it is a potent NRF2 inducer $[14,15]$. Our current results further confirmed that the nuclear translocation of NRF2 is significantly increased by $10 \mu \mathrm{M}$ 4-HNE treatment in HeLa cells (Figure 1). There are several mechanisms proposed for the 4-HNEinduced NRF2 activation. 4-HNE can react with cysteine sites in the KEAP1 protein and that may disrupt the KEAP1-dependent degradation of NRF2 [22]. In addition, 4-HNE may activate NRF2 through activation of upstream kinases such as protein kinase C, extracellular signal-regulated protein kinase and phosphoinositide 3-kinase [14,23,24]. In this study, we showed that 4-HNE could induce nuclear translocation of the NRF2 mutant lacking the KEAP1 binding domain (Figure 1D), indicating that 4-HNE may have a direct effect on NRF2 itself. We found that 4-HNE could modify NRF2 protein in an in vitro testing system (Additional file 1: Figure S1), and future studies will be needed to identify the specific amino acid sites modified by 4-HNE and their impacts in NRF2 signaling. In addition, several studies have reported that 4-HNE treatment leads to dramatic decrease of intracellular GSH [25,26], and depletion of GSH can activate NRF2 signaling [27]. In the present study, we showed that pretreatment of GSH could block the induction of ARE transcriptional activity by 4-HNE (Figure 2B), suggesting that 4-HNE may activate NRF2 via depletion of GSH.

GSTA4 and AKR1C1 are two important enzymes for detoxification of 4-HNE. In the large GST family, GSTA4 is the most active isoform in catalyzing conjugation of GSH to 4-HNE [4]. The higher expression level of GSTA4 in DU145 prostate cancer cells is associated with faster 4-HNE metabolism rate, compared to PC3 or LNCaP prostate cancer cells [28]. It is also reported that overexpression of GSTA4 protects HepG2 cells from 4-HNE mediated oxidative injuries [29]. AKR1C1 has high catalytic activity in reducing 4-HNE to less toxic 1,4-dihydroxynonenol [19]. The role of HO-1 in the detoxification of 4-HNE is not clear. The induction of HO-1 may enhance the overall cellular antioxidant capacity and prevent oxidative stress induced cytotoxicity [15]. Therefore, the induction of gene expression of these cellular protective enzymes by 4-HNE appears to be an adaptive response to enhance elimination of 4-HNE and reduce its toxicity. The transcriptional induction of these detoxifying and antioxidant genes is 


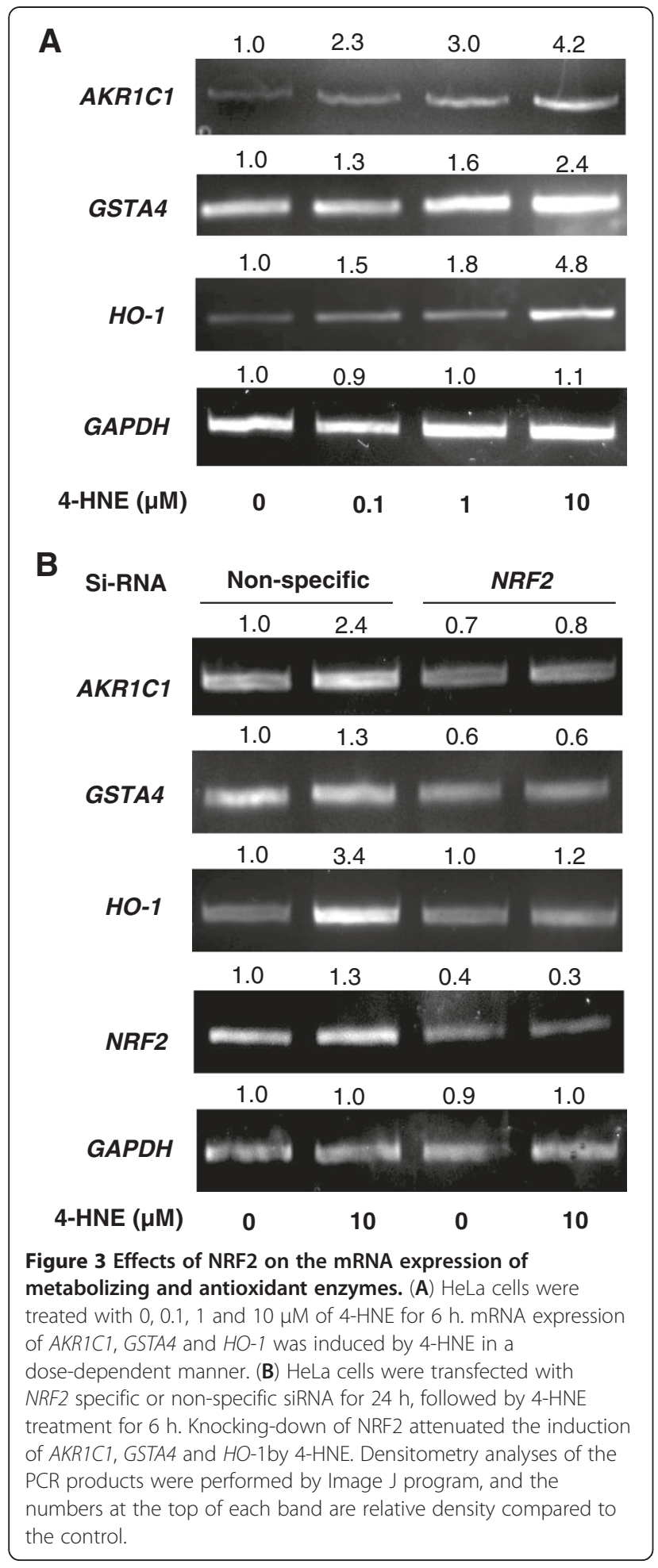

attenuated when NRF2 is knocked down (Figure 3C), indicating that the induction is mediated by NRF2.

\section{Conclusions}

In this study, we demonstrate that NRF2 regulates the enhanced gene expression of antioxidant and detoxifying enzymes by 4-HNE. Our study highlights the importance of the NRF2-ARE signaling mechanism in the detoxification of reactive lipid metabolites such as 4-HNE.

\section{Methods}

Cell culture and chemicals

Human cervical squamous cancerous HeLa cells and human hepatoma HepG2 cells were obtained from ATCC (Manassas, VA). The establishment of stably expressed HepG2 cells with the ARE luciferase reporter was described previously [17]. Cells were cultured in Dolbecco's modified eagle medium supplemented with 10\% FBS. 4-HNE was purchased from Cayman Chemical (Ann Arbor, Michigan).

\section{Cell fractionation and Western blotting}

HeLa cells were treated with $10 \mu \mathrm{M}$ of 4-HNE for 0 , $0.5,1$ and $4 \mathrm{~h}$, and then rinsed with ice-cold PBS and harvested. Nuclear protein was extracted using NEPER nuclear and cytoplasmic protein extraction kits (Thermo scientific) according to the manufacturer's instruction. The protein concentration of each sample was measured, and $10 \mu \mathrm{g}$ of nuclear proteins were used for Western blotting analyses. The details of Western blotting procedures were described previously [30]. Antibodies against NRF2 and Lamin A were from Epitomics and Santa Cruz, respectively. The densitometry of the bands were analyzed by ImageJ program.

\section{Epifluorescent Microscopy}

HeLa cells were cultured on ethanol-sterilized glass coverslips and transfected with $1 \mu \mathrm{g}$ of EGFP-NRF2 or its EGFP-NRF2 $\Delta \mathrm{N}$ using the Lipofectamine method (Invitrogen) and further cultured in DMEM for $24 \mathrm{~h}$. The generation of plasmids was described in our previous study [30]. After transfection, cells were treated with $10 \mu \mathrm{M}$ of 4-HNE for $30 \mathrm{~min}$. The expression and subcellular distribution of EGFP-tagged NRF2 and NRF $2 \Delta \mathrm{N}$ were examined using a Nikon Eclipse E600 epifluorescent microscope and a Nikon C-SHG1 UV light source purchased from Micron-Optics (Cedar Knolls, NJ). The EGFP signals were examined using FITC filters. The epifluorescent images were digitalized using the Nikon DXM1200 camera and Nikon ACT-1 software.

\section{Luciferase Activity Assay}

The HepG2-C8 cell line with a stably expressed pARE-TI-luciferase construct was previously established [17] and used to test the ARE transcriptional activity in this study. Cells were seeded in 6-well plates overnight, and then treated with $10 \mu \mathrm{M}$ of 4HNE for $18 \mathrm{~h}$ with or without pretreatment of $5 \mathrm{mM}$ 
glutathione (GSH) for $2 \mathrm{~h}$. Cells were then washed twice with ice-cold PBS and lysed with $1 \times$ reporter lysis buffer (Promega). A $10 \mu \mathrm{l}$ lysate was mixed with the luciferase substrate (Promega) and the luciferase activity was measured using a Sirius luminometer (Berthold Detection System) and normalized by protein concentration.

\section{Reverse Transcription-PCR}

RNA was extracted using RNeasy mini kit (Qiagen, Valencia, CA) according to manufacturer's instructions and reverse transcribed (RT) using TaqMan ${ }^{\circledR}$ reverse transcription reagents (Applied Biosystems). The RT products were further analyzed by PCR reactions. The sequences of the PCR primers used are listed in Table 1. The RT-PCR products were resolved in $1.5 \%$ agarose gel with ethidium bromide and visualized in UV light.

\section{Transfection with siRNA}

The sense and antisense sequences of siRNA against $N R F 2$ and nonspecific sequences were described previously [31]. The siRNA oligomers were synthesized by Integrated DNA technologies. HeLa cells were transfected using Lipofectamin RNAiMAX reagent (Invitrogen) following the manufacturer's instructions. Cells were transfected for $48 \mathrm{~h}$ with $50 \mathrm{nM}$ siRNA in Opi-MEM medium without antibiotics and serum. Then, the cells were treated with $10 \mu \mathrm{M}$ 4-HNE for $6 \mathrm{~h}$.

\section{Statistical analyses}

Fold induction of $A R E$-luciferase and relative densitometry of nuclear NRF2 protein were analyzed using one-way ANOVA, where 4-HNE concentration or the exposure time of 4-HNE was treated as the main effect, followed by Tukey's studentized range test.

\section{Table 1 Oligonucleotide primers used for PCR}

\begin{tabular}{|c|c|c|}
\hline Gene & NCBI ID & Primer sequence \\
\hline \multirow[t]{2}{*}{ GAPDH } & NM_002046.3 & Forward 5'-AAGGTCGGAGTCAACGGATTTGGT-3' \\
\hline & & Reverse 5'- ACAAAGTGGTCGTTGAGGGCAATG-3' \\
\hline \multirow[t]{2}{*}{ AKRIC1 } & NN & 5'- AGCTTTGGTGCAATTCCCATCGAC-3' \\
\hline & & Reverse 5'- GGGCTITGCTGTAGCTTGCTGAAA-3' \\
\hline \multirow[t]{2}{*}{ GSTA4 } & NM_001512.3 & Forward 5'- TGAAGTTGGTACAGACCCGAAGCA-3' \\
\hline & & Reverse 5'- ACCATGACAGAGCTGGGATCCATT-3' \\
\hline \multirow[t]{2}{*}{$\mathrm{HO}-1$} & NM_002133 & Forward 5'- AGGAGATTGAGCGCAACAAGGAGA-3 \\
\hline & & Reverse 5'- TCGCCACCAGAAAGCTGAGTGTAA-3' \\
\hline
\end{tabular}

\section{Additional file}

Additional file 1: Figure S1. NRF2 protein is modified by 4-HNE. Purified $6 \times$ His-NRF2 protein $(10 \mu \mathrm{g}, 0.146 \mathrm{nmol})$ was incubated with different molar excess of 4-HNE in $30 \mu \mathrm{L}$ phosphate buffer

$(50 \mathrm{mM}, \mathrm{pH}=7.4)$ for $30 \mathrm{~min}$. Reaction was terminated by adding $10 \mu \mathrm{L}$ of Laemmli's SDS buffer and samples were boiled at $95^{\circ} \mathrm{C}$. $20 \mu \mathrm{L}$ of each sample was subject to Western blotting analyses. Primary anti-4-HNE antibody (Alpha Diagnostic) was used to detect 4-HNE modifications. Then, the primary antibody was stripped off and anti-NRF2 antibody was used to detect NRF2 protein as a loading control.

\section{Abbreviations}

ARE: Antioxidant response elements; AKR1C1: Aldoketone reductase 1C1; EGFP: The enhanced green fluorescent protein; GSH: Glutathione; GSTA4: Glutathione S-transferase A4; HO-1: Heme oxygenase-1; 4-HNE: 4-hydroxynonenal; KEAP1: Kelch-like ECH-associated protein 1; NRF2: NF-E2-related factor 2.

\section{Competing interests}

The authors declare that they have no competing interests.

\section{Authors' contributions}

$\mathrm{YH}$ and $\mathrm{WL}$ designed, conducted the experiments, analyzed the data and wrote the manuscript; ANK designed, supervised the experiments and edited the manuscript; ANK has the primary responsibility for the final content; all the authors read and approved the final version of the manuscript.

\section{Acknowledgements}

The authors thank members in Dr. Kong's group for discussions and technical support. This work was supported in part by NIH R01-CA118947, R01-CA152826, R01AT007065 from NCCAM and ODS, and P30ES005022.

\section{Author details}

'Department of Pharmaceutics, Center for Cancer Prevention Research, Ernest Mario School of Pharmacy, Rutgers, the State University of New Jersey, 160 Frelinghuysen Road, Piscataway, NJ 08854, USA. ²Present address: Department of Genetics, Albert Einstein College of Medicine, 1301 Morris Park Avenue, Bronx, NY 10461, USA.

Received: 20 May 2012 Accepted: 8 October 2012 Published: 28 November 2012

\section{References}

1. Catala A: Lipid peroxidation of membrane phospholipids generates hydroxy-alkenals and oxidized phospholipids active in physiological and/or pathological conditions. Chem Phys Lipids 2009, 157:1-11.

2. Esterbauer $\mathrm{H}$, Schaur RJ, Zollner H: Chemistry and biochemistry of 4-hydroxynonenal, malonaldehyde and related aldehydes. Free Radic Biol Med 1991, 11:81-128.

3. Siems W, Grune T: Intracellular metabolism of 4-hydroxynonenal. Mol Aspects Med 2003, 24:167-175.

4. Awasthi YC, Ansari GA, Awasthi S: Regulation of 4-hydroxynonenal mediated signaling by glutathione S-transferases. Methods Enzymol 2005, 401:379-407.

5. Petersen DR, Doorn JA: Reactions of 4-hydroxynonenal with proteins and cellular targets. Free Radic Biol Med 2004, 37:937-945.

6. Smathers RL, Galligan JJ, Stewart BJ, Petersen DR: Overview of lipid peroxidation products and hepatic protein modification in alcoholic liver disease. Chem Biol Interact 2011, 192:107-112.

7. Jaiswal AK: Nrf2 signaling in coordinated activation of antioxidant gene expression. Free Radic Biol Med 2004, 36:1199-1207.

8. Xie T, Belinsky M, XU Y, Jaiswal AK: ARE- and TRE-mediated regulation of gene expression. Response to xenobiotics and antioxidants. J Biol Chem 1995, 270:6894-6900.

9. Shen G, Kong AN: Nrf2 plays an important role in coordinated regulation of Phase II drug metabolism enzymes and Phase III drug transporters. Biopharm Drug Dispos 2009, 30:345-355.

10. Itoh K, Chiba T, Takahashi S, Ishii T, Igarashi K, Katoh Y, Oyake T, Hayashi N, Satoh K, Hatayama I, Yamamoto M, Nabeshima Y: An Nrf2/small Maf 
heterodimer mediates the induction of phase II detoxifying enzyme genes through antioxidant response elements. Biochem Biophys Res Commun 1997, 236:313-322.

11. Kensler TW, Wakabayashi N: Nrf2: friend or foe for chemoprevention? Carcinogenesis 2010, 31:90-99.

12. Motohashi H, Yamamoto M: Nrf2-Keap1 defines a physiologically important stress response mechanism. Trends Mol Med 2004, 10:549-557.

13. Li W, Kong AN: Molecular mechanisms of Nrf2-mediated antioxidant response. Mol Carcinog 2009, 48:91-104.

14. Chen ZH, Saito Y, Yoshida Y, Sekine A, Noguchi N, Niki E: 4-Hydroxynonenal induces adaptive response and enhances PC12 cell tolerance primarily through induction of thioredoxin reductase 1 via activation of Nrf2. J Biol Chem 2005, 280:41921-41927.

15. Ishikado A, Nishio Y, Morino K, Ugi S, Kondo H, Makino T, Kashiwagi A, Maegawa H: Low concentration of 4-hydroxy hexenal increases heme oxygenase-1 expression through activation of Nrf2 and antioxidative activity in vascular endothelial cells. Biochem Biophys Res Commun 2010, 402:99-104

16. Katoh Y, lida K, Kang MI, Kobayashi A, Mizukami M, Tong Kl, McMahon M, Hayes JD, Itoh K, Yamamoto M: Evolutionary conserved N-terminal domain of Nrf2 is essential for the Keap1-mediated degradation of the protein by proteasome. Arch Biochem Biophys 2005, 433:342-350.

17. Yu R, Mandlekar S, Lei W, Fahl WE, Tan TH, Kong AN: p38 mitogenactivated protein kinase negatively regulates the induction of phase II drug-metabolizing enzymes that detoxify carcinogens. J Biol Chem 2000, 275:2322-2327.

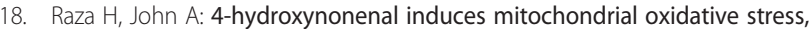
apoptosis and expression of glutathione S-transferase A4-4 and cytochrome P450 2E1 in PC12 cells. Toxicol Appl Pharmacol 2006, 216:309-318.

19. Burczynski ME, Sridhar GR, Palackal NT, Penning TM: The reactive oxygen species-and Michael acceptor-inducible human aldo-keto reductase AKR1C1 reduces the alpha, beta-unsaturated aldehyde 4-hydroxy-2nonenal to 1,4-dihydroxy-2-nonene. J Biol Chem 2001, 276:2890-2897.

20. Hayes JD, Flanagan JU, Jowsey IR: Glutathione transferases. Annu Rev Pharmacol Toxicol 2005, 45:51-88.

21. Burczynski ME, Lin HK, Penning TM: Isoform-specific induction of a human aldo-keto reductase by polycyclic aromatic hydrocarbons (PAHs), electrophiles, and oxidative stress: implications for the alternative pathway of PAH activation catalyzed by human dihydrodiol dehydrogenase. Cancer Res 1999, 59:607-614.

22. Levonen AL, Landar A, Ramachandran A, Ceaser EK, Dickinson DA, Zanoni G, Morrow JD, Darley-Usmar VM: Cellular mechanisms of redox cell signalling: role of cysteine modification in controlling antioxidant defences in response to electrophilic lipid oxidation products. Biochem J 2004, 378:373-382.

23. Numazawa S, Ishikawa M, Yoshida A, Tanaka S, Yoshida T: Atypical protein kinase $C$ mediates activation of NF-E2-related factor 2 in response to oxidative stress. Am J Physiol Cell Physiol 2003, 285:C334-C342.

24. Chen J, Wang L, Chen Y, Sternberg P, Cai J: Phosphatidylinositol 3 kinase pathway and 4-hydroxy-2-nonenal-induced oxidative injury in the RPE. Invest Ophthalmol Vis Sci 2009, 50:936-942.

25. Long EK, Murphy TC, Leiphon LJ, Watt J, Morrow JD, Milne GL, Howard JR, Picklo MJ Sr: Trans-4-hydroxy-2-hexenal is a neurotoxic product of docosahexaenoic (22:6; n-3) acid oxidation. J Neurochem 2008, 105:714-724.

26. Vladykovskaya E, Sithu SD, Haberzettl P, Wickramasinghe NS, Merchant ML, Hill BG, McCracken J, Agarwal A, Dougherty S, Gordon SA, Schuschke DA, Barski OA, O'Toole T, D'Souza SE, Bhatnagar A, Srivastava S: Lipid peroxidation product 4-hydroxy-trans-2-nonenal causes endothelial activation by inducing endoplasmic reticulum stress. J Biol Chem 2012, 287:11398-11409.

27. Copple IM, Goldring CE, Jenkins RE, Chia AJ, Randle LE, Hayes JD, Kitteringham NR, Park BK: The hepatotoxic metabolite of acetaminophen directly activates the Keap1-Nrf2 cell defense system. Hepatology 2008, 48:1292-1301.

28. Pettazzoni P, Ciamporcero E, Medana C, Pizzimenti S, Dal Bello F, Minero VG, Toaldo C, Minelli R, Uchida K, Dianzani MU, Pili R, Barrera G: Nuclear factor erythroid 2-related factor-2 activity controls 4-hydroxynonenal metabolism and activity in prostate cancer cells. Free Radic Biol Med 2011, 51:1610-1618.
29. Gallagher EP, Huisden CM, Gardner JL: Transfection of HepG2 cells with hGSTA4 provides protection against 4-hydroxynonenal-mediated oxidative injury. Toxicol In Vitro 2007, 21:1365-1372.

30. Kim JH, Yu S, Chen JD, Kong AN: The nuclear cofactor RAC3/AIB1/SRC-3 enhances Nrf2 signaling by interacting with transactivation domains. Oncogene 2012, Epub ahead of print.

31. Singh A, Misra V, Thimmulappa RK, Lee H, Ames S, Hoque MO, Herman JG, Baylin SB, Sidransky D, Gabrielson E, Brock MV, Biswal S: Dysfunctional KEAP1-NRF2 interaction in non-small-cell lung cancer. PLoS Med 2006, 3:e420.

doi:10.1186/2045-3701-2-40

Cite this article as: Huang et al:: Anti-oxidative stress regulator NF-E2-related factor 2 mediates the adaptive induction of antioxidant and detoxifying enzymes by lipid peroxidation metabolite 4-hydroxynonenal. Cell \& Bioscience 2012 2:40.

\section{Submit your next manuscript to BioMed Central and take full advantage of:}

- Convenient online submission

- Thorough peer review

- No space constraints or color figure charges

- Immediate publication on acceptance

- Inclusion in PubMed, CAS, Scopus and Google Scholar

- Research which is freely available for redistribution

Submit your manuscript at www.biomedcentral.com/submit
C Biomed Central 